\title{
Knowledge, Attitudes and Practices of Parents with Children under 6 Years Old Referring to Health Centers in Hamadan Regarding Fever Control
}

\author{
Monireh Afshari $(\mathrm{BSc})^{1}$, Leyli Tapak $(\mathrm{PhD})^{2}$, Morteza Shamsiadeh $(\mathrm{MSc})^{3}$, Majid \\ Barati $(\mathbf{P h D})^{4, *}$ \\ ${ }^{I}$ Students Research Committee, Hamadan University of Medical Sciences, Hamadan, Iran \\ ${ }^{2}$ Department of Biostatistic, School of Public Health, Hamadan University of Medical Sciences, Hamadan, Iran \\ ${ }^{3}$ School of Nursing and Midwifery, Hamadan University of Medical Sciences, Hamadan, Iran \\ ${ }^{4}$ Social Determinants of Health Research Center and Department of Public Health, Hamadan University of Medical \\ Sciences, Hamadan, Iran \\ * Corresponding Author: Majid Barati, Social Determinants of Health Research Center and Department of Public Health, \\ Hamadan University of Medical Sciences, Hamadan, Iran.Email: barati@umsha.ac.ir
}

\begin{tabular}{|c|c|}
\hline & Abstract \\
\hline $\begin{array}{l}\text { Received: } 13 / 02 / 2018 \\
\text { Accepted: } 07 / 03 / 2018\end{array}$ & \multirow[b]{2}{*}{$\begin{array}{l}\text { Background and Objective: Control of fever in children is one of the most } \\
\text { common reasons for parents to seek medical care and medical attention in } \\
\text { health centers. Thus, the aim of this study was to investigate the } \\
\text { knowledge, attitudes and practices of parents with children under } 6 \text { years } \\
\text { old referring to health centers in Hamadan regarding fever control. } \\
\text { Materials and Methods: This cross-sectional study was carried out on } 504 \\
\text { parents with children under } 6 \text { years old in Hamadan who health centers } \\
\text { were selected by cluster sampling and parents were selected by } \\
\text { convenience sampling method in } 2017 \text {. Data collection tools consisted of a } \\
\text { questionnaire in four sections: demographic data, parents' knowledge, } \\
\text { attitude and practice. Data were analyzed using independent t-test, one way } \\
\text { ANOVA and Pearson correlation coefficient in SPSS-16 software. } \\
\text { Results: The subjects reported } 83.9 \% \text {, } 49.6 \% \text {, and } 86.9 \% \text { of receivable } \\
\text { scores of knowledge, attitudes and practices, respectively. Parents' } \\
\text { knowledge in controlling fever was reported as undesirable. However, the } \\
\text { parents' attitude and practices were at a satisfactory level. There is also a } \\
\text { positive and significant correlation between knowledge, attitude and } \\
\text { practice. There is a positive and significant correlation between parent's } \\
\text { knowledge, attitude and practices (P<0.01). } \\
\text { Conclusion: According to the unfavorable level of parents' knowledge, it } \\
\text { is essential to consider plan for teaching parents in the management of } \\
\text { childhood fever control methods at home by health care providers. }\end{array}$} \\
\hline $\begin{array}{l}\text { How to Cite this Article: } \\
\text { Afshari M, Tapak L, } \\
\text { Shamsiadeh M, Barati M. } \\
\text { Knowledge, Attitudes and } \\
\text { Practices of Parents with } \\
\text { Children under } 6 \text { Years Old } \\
\text { Referring to Health Centers in } \\
\text { Hamadan Regarding Fever } \\
\text { Control. Pajouhan Scientific } \\
\text { Journal. 2018; 16(3): 58-66. } \\
\text { DOI: 10.18869/psj.16.3.58 }\end{array}$ & \\
\hline & Keywords: Attitudes; Child; Fever Control; Knowledge; Parents \\
\hline
\end{tabular}


dof: $10.18869 /$ psj. 16.3 .58

\section{بررسى آكاهى، نكرش و عملكرد والدين داراى كودى زير 9 سال مراجعه كننده به مراكز} بهل اشتى درمانى شهر همدان در خصوص كنتر لت تب

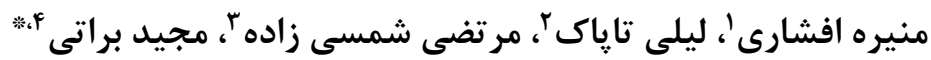

' كارشناس، كميته تحقيقات دانشجويى، دانشخاه علوم يزشكى همدان، همدان، ايران

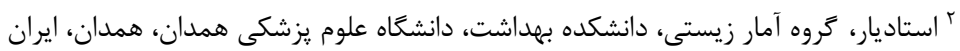

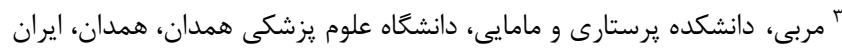

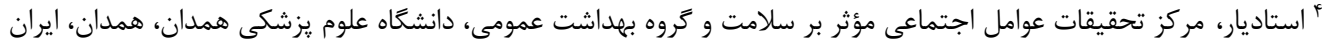
* نويسنده مسئول: مجيد براتى، مركز تحقيقات عوامل اجتماعى مؤثر بر سلامت و گروه بهداشت عمومى، دانشعاه علوم يزشكى همدان، همدان، ايران.

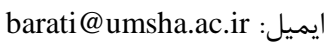

\section{جكيده}

سابقه و هدف: كنترل تب در كودكان يكى از شايعترين عللى است كه والدين را جهت جست و جوى

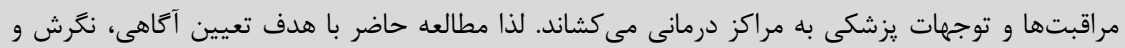

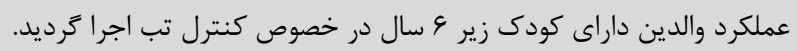

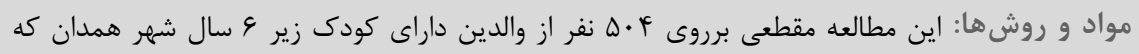

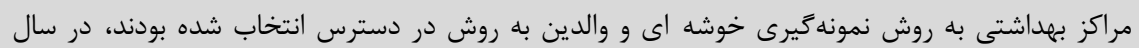

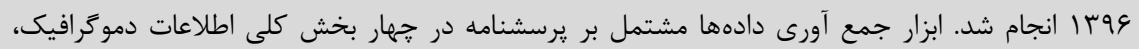

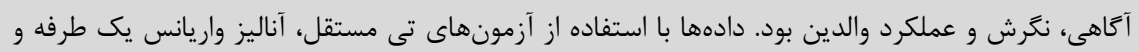

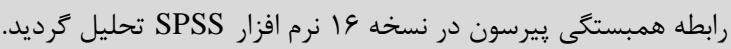

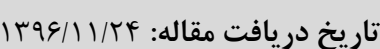

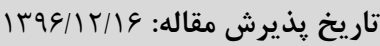
تمامى حقوق نشر براى دانشكاه علوم يزشكى همدان محفوظ است.

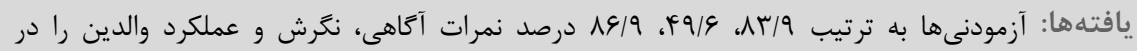

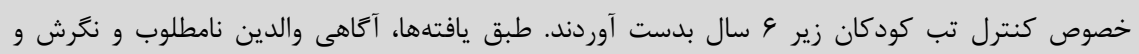

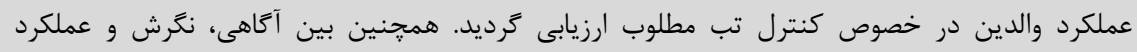

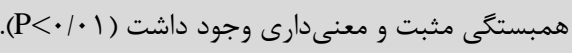

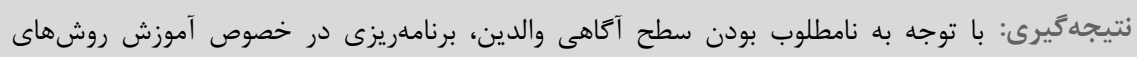

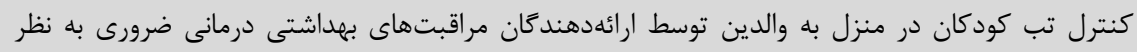
مىرسد. وازَٔان كليدى: آكاهى؛ كنترل تب؛ كودكان؛ نكرش؛ والدين

مقلdمه

محسوب و موجب نكرانى آنها مىشود [F]. تحقيقات نشان داده است كه تب در كودكان يكى از شايعترين عللى كه

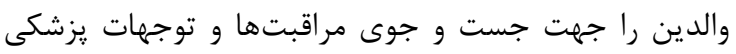
به كلينيكهاى اطفال مي كشاند [F-V]

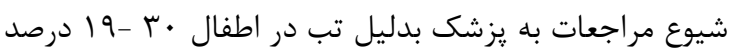
و در منابع ديگر حدود •ه درصد تخمين زده اند [؟،ه،ه].

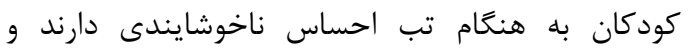

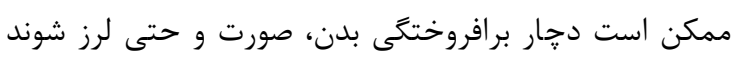

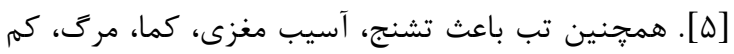

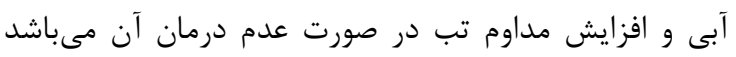

تب عبارت است از افزايش درجه حرارت بدن بيش از حد

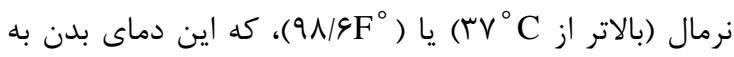

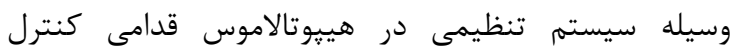

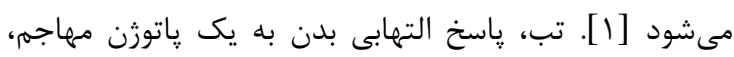

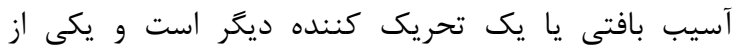

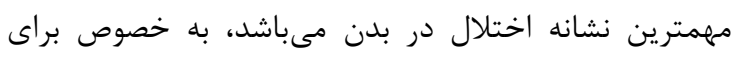

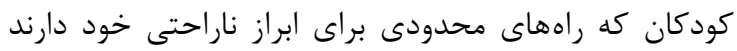

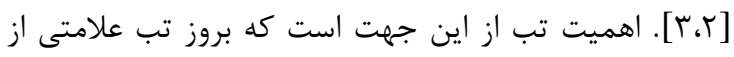

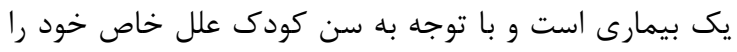

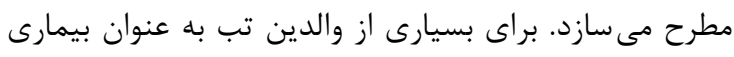


نامناسب بعضا ايجاد مسموميت در اثر مصرف غير استاندارد

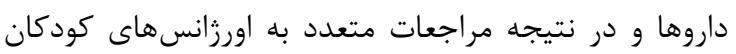

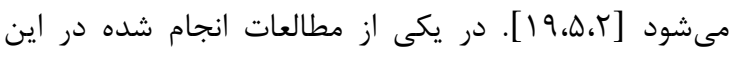

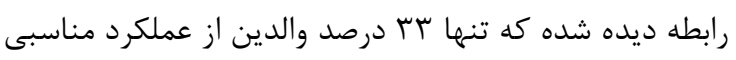
به هنگام وقوع تب در كودى خود برخوردار بودند [ها].

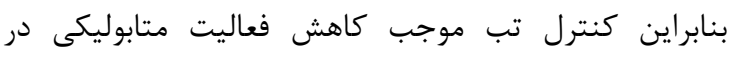

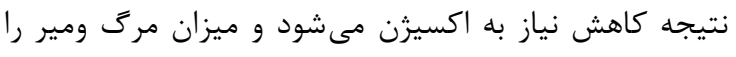

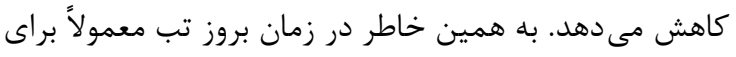

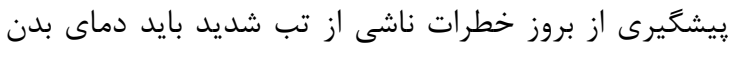

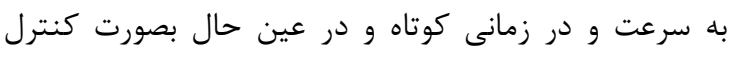

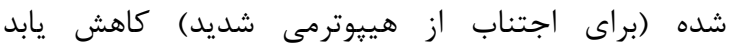

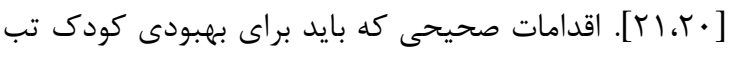

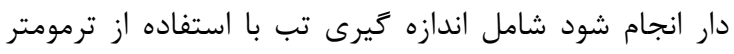

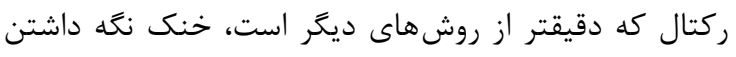

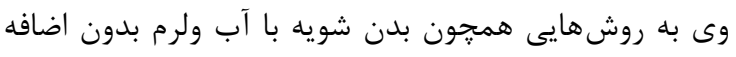

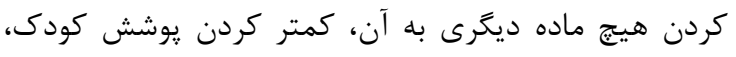

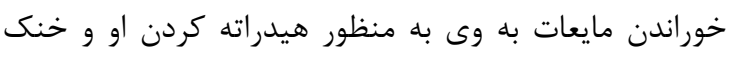
نكَهداشتن محيط و دماى اتاق كودى ميى باشد. البته كنترل

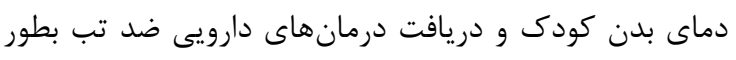

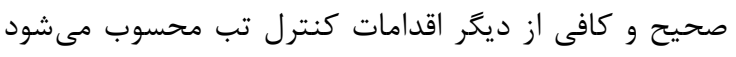

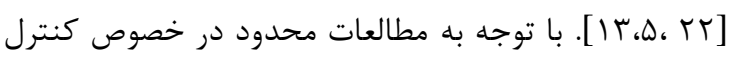
تب در كودكان و عدم اطلاع از وضعيت موجود، مطالعه

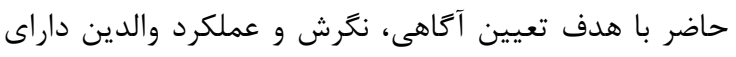

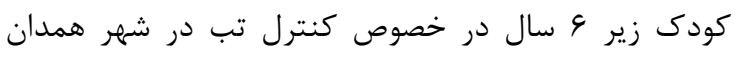

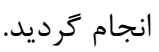

\section{مواد و روشها}

يزوهش حاضر يك مطالعه توصيفى از نوع مقطعى بود كه

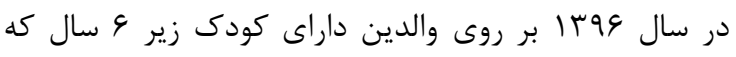
جهت معاينه روتين يا به علت بيمارى كودى خود به به درائ دراكز

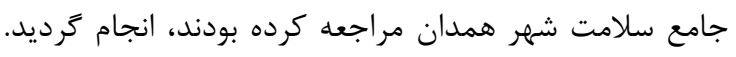

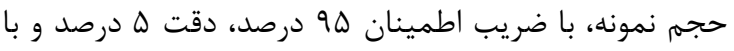

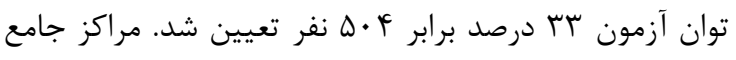

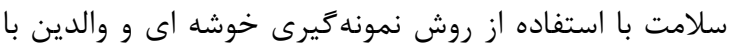

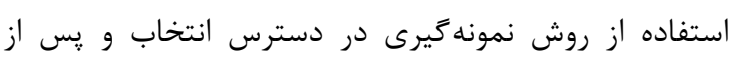

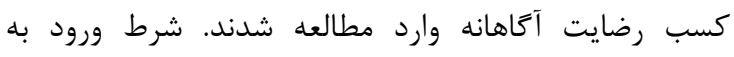

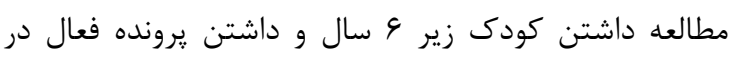

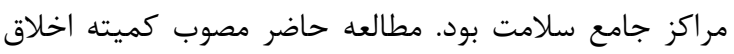

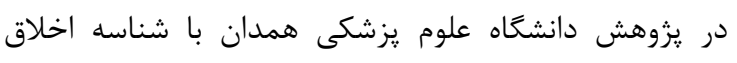

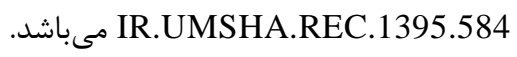

اطلاعات مورد نظر از طريق يرسشنامهاى كه شامل

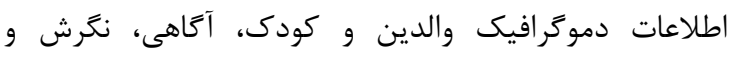

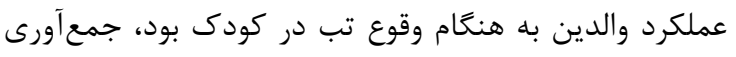

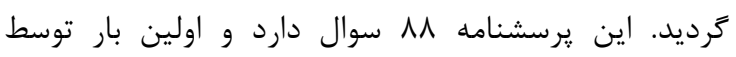

[r]]. ايجاد تب به هنًَام واكنش به آزادسازى عوامل تبزاى

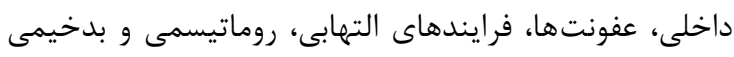

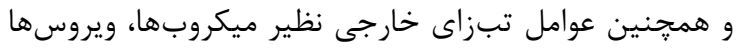

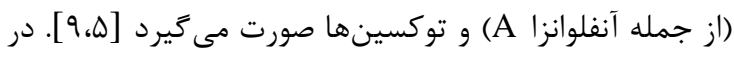
واقع تب زمانى اتفاق مى افتد كه يا نقطه تنظيم دما در

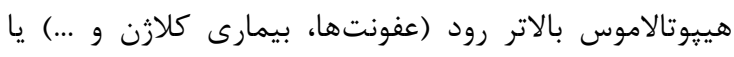

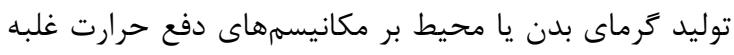

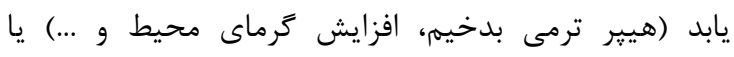
مكانيسمهاى دفع حرارت دجار نقص شود (ديسيلازى درم).

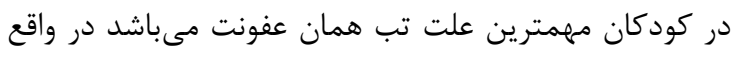

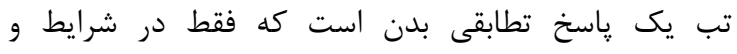

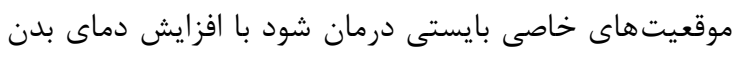

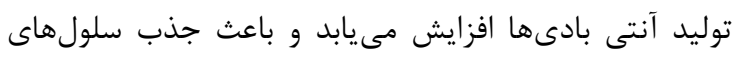
دفاعى به محل عفونت مى شود و خاصيت بيكانه خوارى آنها

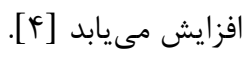

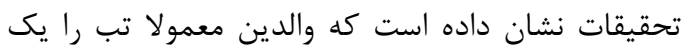

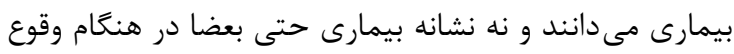

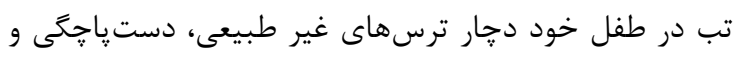
هراس شده و كنترل خود را از دست مى دهند كند كه از آن آن در

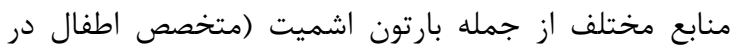

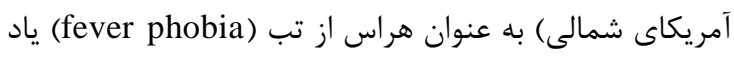

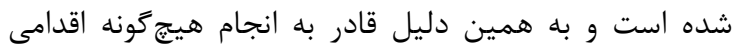

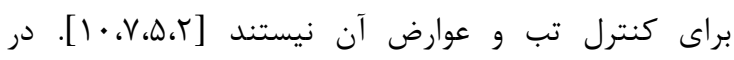

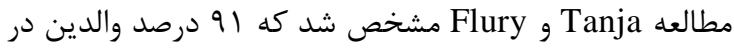

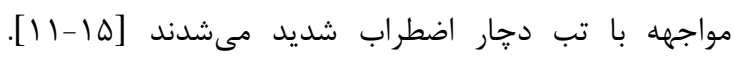
درخصوص اين ترسها و رفتارهاى غيرمنطقى با تب، در برخى مطالعات آمده است كه تنها در يكى سوم موارد والدين

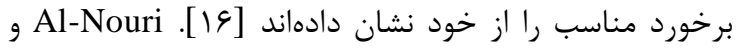

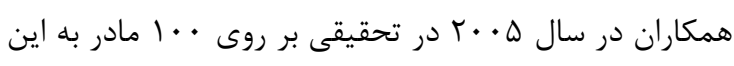

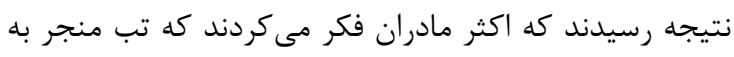

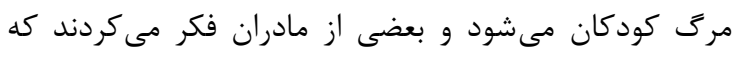
ممكن است به فلج، عقبماندگى يا آسيبهاى مغزى مادر منجر

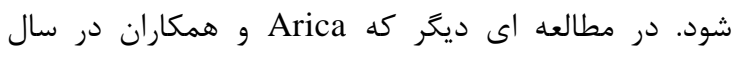

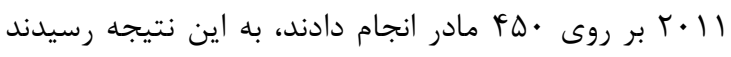

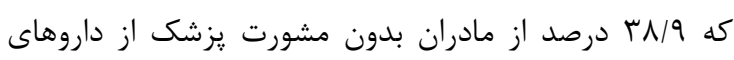

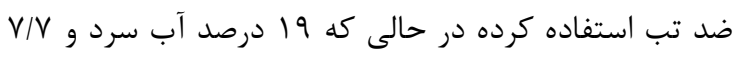
درصد آب و الكل يا سركه استفاده مى كردند كه در در ميان دان

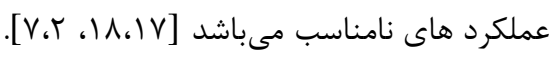

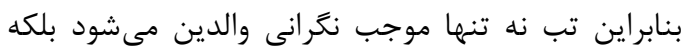

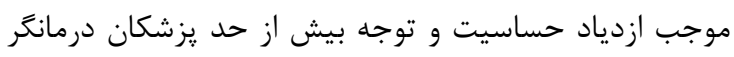

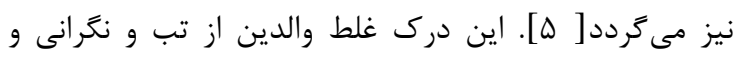
ترس بيش از حد آنان موجب تكرار مراجعات به مراكز

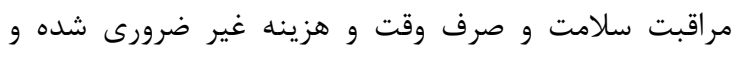

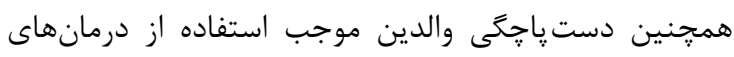


كودكان مورد مطالعه داراى سابقه تشنج و 9 • 1 درصد نيز

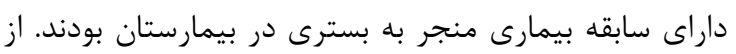

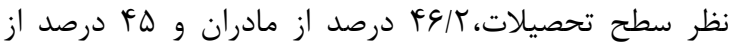
يدران داراى مدرك تحصيلى راهنمايى يا دييلم بودند.

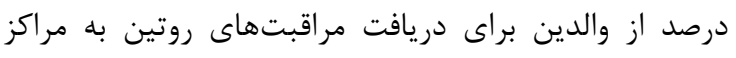
جامع سلامت مراجعه كرده بودند.

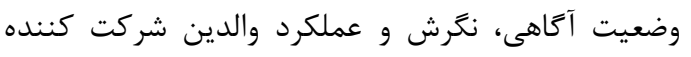

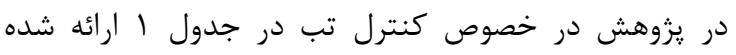

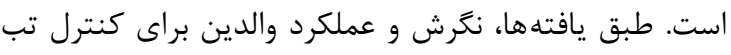

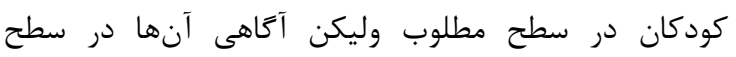
نامطلوبى ارزيابى كرديد.

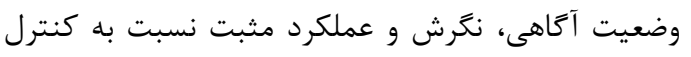

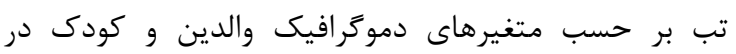

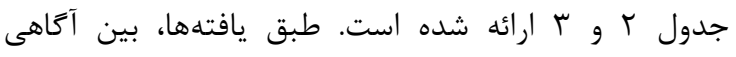

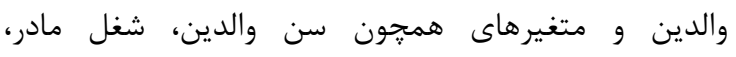

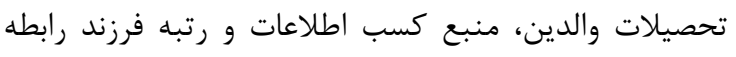

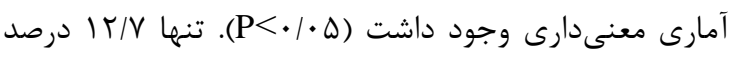

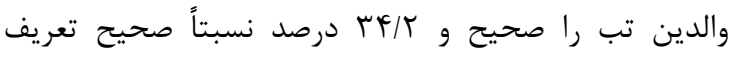

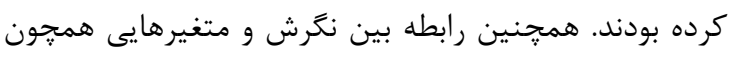

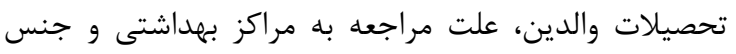

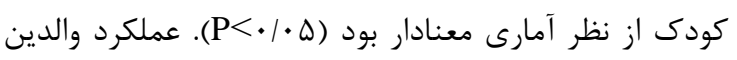

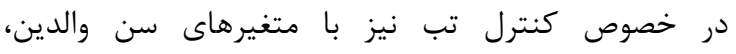
تحصيلات والدين، منبع كسب اطلاعات و و رتبه فرزند رند رابطه

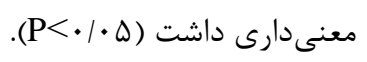

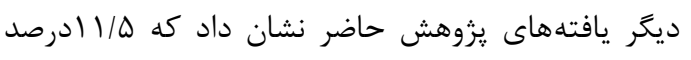

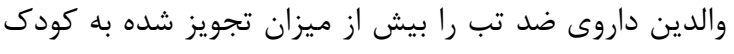

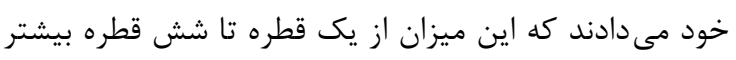

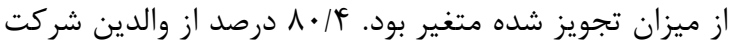

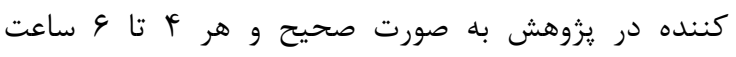

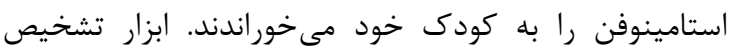

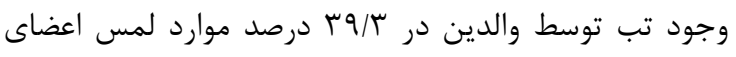

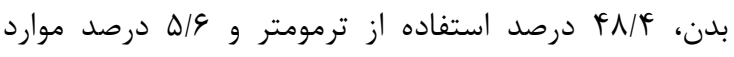

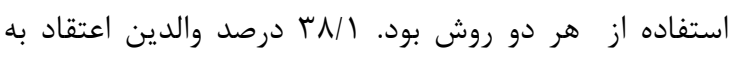

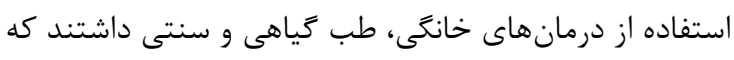

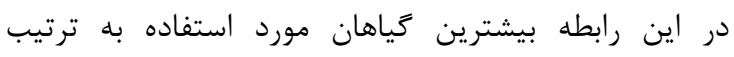

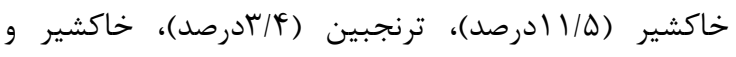

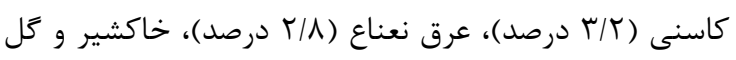

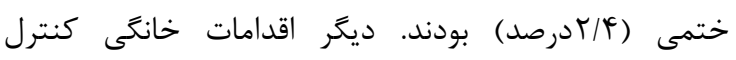

رشادت و همكاران طراحى و مورد استفاده قرار كرفت [ه].

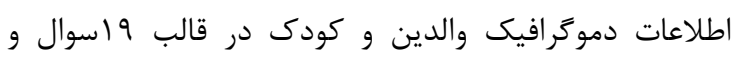

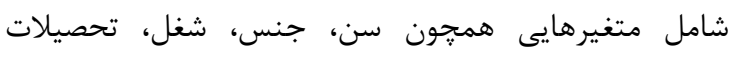

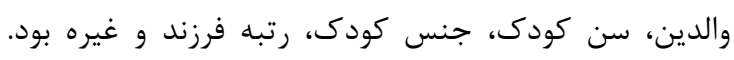

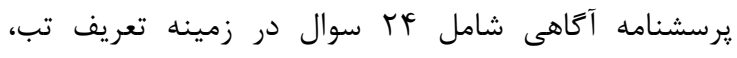

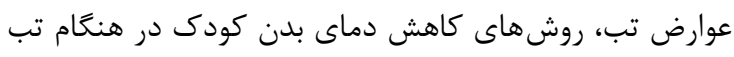

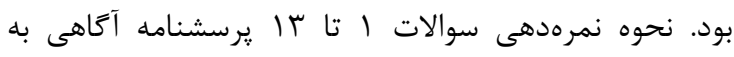

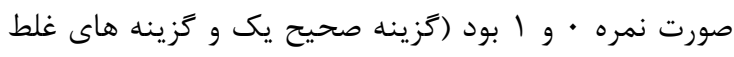

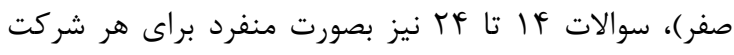

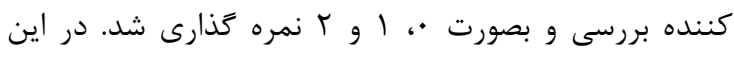

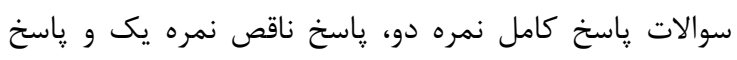

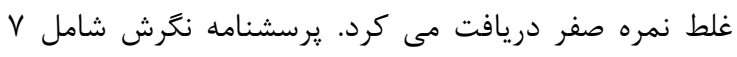

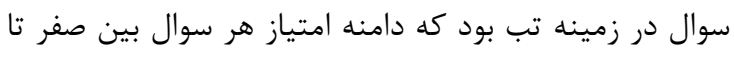

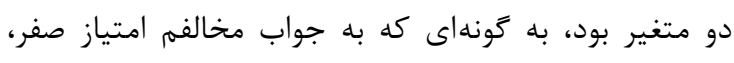

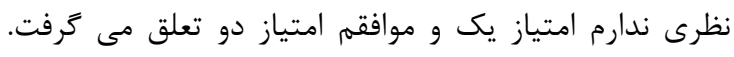

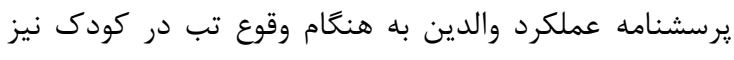

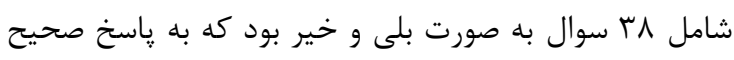

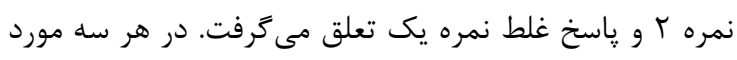

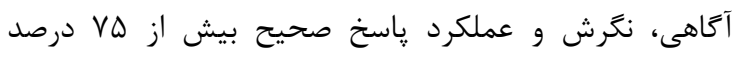

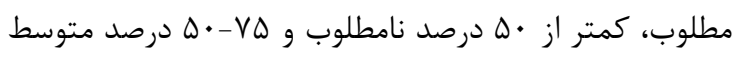

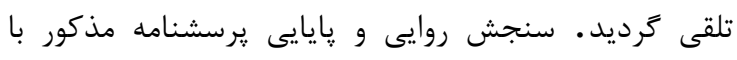

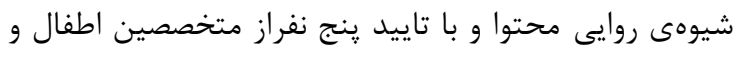

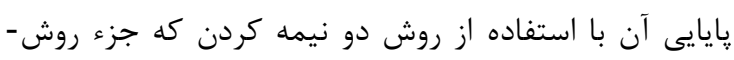

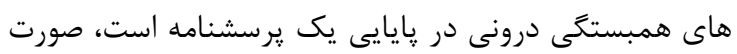

كرفت [ه] [مائ.

دادهاى بدست آمده يّ از وارد كردن در نسخه 9 آنرم

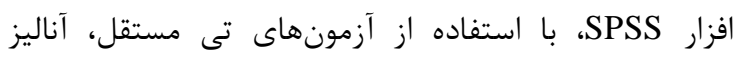

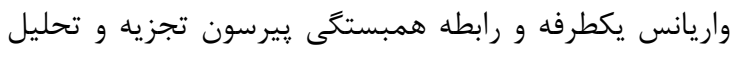

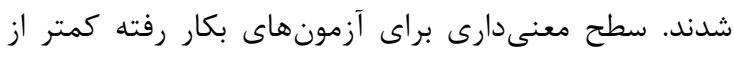

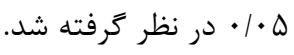

\section{يافته ها}

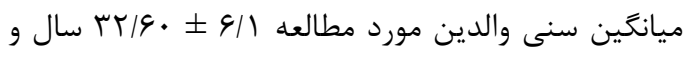
ميانكين سنى كودكانشان

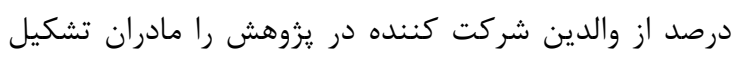

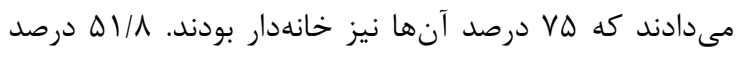

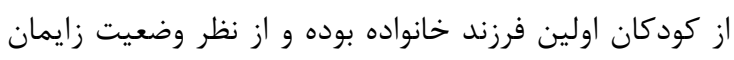

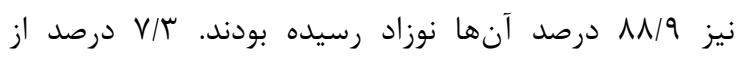

جدول ا: وضعيت آكاهى، نكرش و عملكرد در خصوص كنترل تب در بين شركت كنندكان در يزوهش متش

\begin{tabular}{|c|c|c|c|c|}
\hline ميانتين土|نحراف معيار & تعداد (درصد) & تعداد (درصد) & تعداد (درصد) مطلوب & متغيرهاى مطالعه \\
\hline $11 / \varepsilon \cdot \pm r / \Delta$ & Frr(^r/Q) & $\vee 9(1 \Delta / V)$ & $r(\cdot / \boldsymbol{F})$ & آكاهى \\
\hline $1 \cdot / r T \pm r / \cdot 1$ & $19(T / Y)$ & $r \Psi \wedge(F V / T)$ & $r \Delta \cdot(r q / \varphi)$ & ن نَرش \\
\hline$\Delta \cdot / 19 \pm \Gamma / T F$ & -- & $99(\mid r / 1)$ & 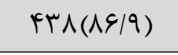 & عملكرد \\
\hline
\end{tabular}




\begin{tabular}{|c|c|c|c|c|c|c|c|}
\hline \multicolumn{2}{|c|}{ عملكرد } & \multicolumn{2}{|r|}{ نَرش } & \multicolumn{2}{|c|}{ آكاهى } & & \\
\hline P-value & 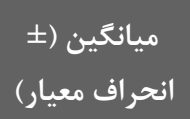 & P-value & 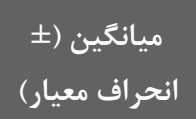 & P-value & 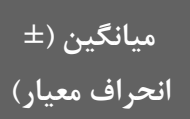 & & \\
\hline$\cdot 10 \cdot 9$ & $\begin{array}{l}F q / r r( \pm r / r) \\
\Delta \cdot / \Delta r( \pm r / l)\end{array}$ & $\cdot / 1009$ & $\begin{array}{l}1 \cdot / T \varepsilon( \pm r / \cdot) \\
1 \cdot / r F( \pm r / \cdot)\end{array}$ & . & $\begin{array}{l}11 / \% q( \pm F / \Lambda) \\
11 / \varepsilon \wedge( \pm F / \Lambda)\end{array}$ & زمن & جنس \\
\hline$\cdot 1090$ & $\begin{array}{l}\Delta I / r F( \pm r / r) \\
F q / \wedge \Delta( \pm r / 1)\end{array}$ & $\cdot \mid \Lambda V^{f}$ & $\begin{array}{l}1 \cdot / \Lambda \Lambda( \pm r / \cdot) \\
1 \cdot / 1 r( \pm / / 9)\end{array}$ & $\cdot 1 \cdot \cdot r$ & 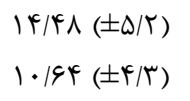 & خاغل & شغل مادر \\
\hline . IVEV & $\begin{array}{l}\omega \cdot / \mathcal{\Psi} \cdot( \pm r / r) \\
\omega \cdot / 1 \varphi( \pm r / r)\end{array}$ & מדואי & $\begin{array}{l}1 \cdot / 9 \wedge( \pm / / \Lambda) \\
1 \cdot / r \&( \pm r / \cdot)\end{array}$ & . $/ F F$. & $\begin{array}{l}\mid r / V V( \pm \Delta / \mathcal{F}) \\
\mid \mathbb{F} \cdot( \pm F / V)\end{array}$ & خلى & سابقه نازايى \\
\hline $.1 \cdot 19$ & $\begin{array}{l}\Delta \cdot / \Delta F( \pm r / \Delta) \\
\Delta \cdot / \Delta \mid( \pm r / T) \\
\Delta \cdot / 19( \pm r / 1) \\
F \wedge / 9 T( \pm r / \Delta)\end{array}$ & $\cdot 1 \cdot \Delta F$ & $\begin{array}{l}9 / 99( \pm / / \Lambda) \\
1 \cdot / r \wedge( \pm r / \cdot) \\
1 \cdot / 4)( \pm r / \cdot) \\
9 / \Delta \cdot( \pm / / 9)\end{array}$ & $\cdot / \cdot r$ & 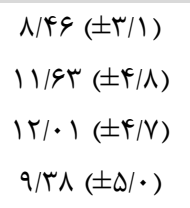 & 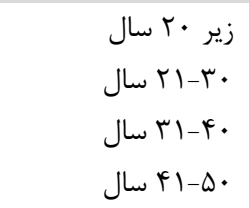 & سن \\
\hline$<\cdot \mid \cdot \cdot 1$ & $\begin{array}{l}\text { F्/DF }( \pm Y / \varphi) \\
\text { FN/AV }( \pm r / \Lambda) \\
\Delta \cdot / 1 \cdot( \pm r / 1) \\
\Delta I / r T( \pm r / 1)\end{array}$ & $<\cdot|\cdot \cdot|$ & $\begin{array}{l}9 / \Gamma \wedge( \pm 1 / 9) \\
9 / \Delta 9( \pm r / \cdot) \\
1 \cdot / r \Delta( \pm / / 9) \\
1 \cdot / \Lambda \wedge( \pm 1 / 9)\end{array}$ & $<\cdot 1 \cdots 1$ & 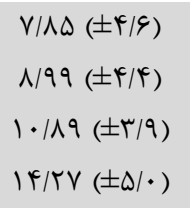 & بيسواد & تحصيلات \\
\hline$<\cdot \mid \cdot \cdot 1$ & $\begin{array}{l}\uparrow \Delta / \Delta \wedge( \pm r / \varphi) \\
\& q / r /( \pm r / Y) \\
\Delta \cdot / \cdot \Delta( \pm r / l) \\
\Delta 1 / \cdot \varphi( \pm r / r)\end{array}$ & $<\cdot|\cdot \cdot|$ & $\begin{array}{l}\text { N/FT }( \pm / / \Lambda) \\
9 / D /( \pm T / \cdot) \\
1 \cdot / T r( \pm / / \Lambda) \\
1 \cdot / 9 T( \pm / / 9)\end{array}$ & $<\cdot 1 \cdot \bullet 1$ & $\begin{array}{l}r / q r( \pm r / l) \\
q / \vee \Delta( \pm r / r) \\
11 / \cdot \wedge( \pm r / r) \\
1 r / F \wedge( \pm \Delta / 1)\end{array}$ & بيسواد & تحصيلات \\
\hline$<\cdot \mid \cdot \cdots$ & $\begin{array}{l}\Delta \cdot / \& \wedge( \pm r / r) \\
\& q / F \mathcal{F}( \pm r / q) \\
\Delta \cdot / \cdot \vee( \pm r / r) \\
\Delta \cdot / r q( \pm r / \cdot) \\
F \wedge / \& \wedge( \pm r / r)\end{array}$ & . & $\begin{array}{l}1 \cdot / \mathbb{E} T( \pm / / 9) \\
9 / \Delta r( \pm r / \mathbb{F}) \\
1 \cdot / A V( \pm / / \Delta) \\
1 \cdot / \mathbb{F} \cdot( \pm / / 9) \\
1 \cdot / l \cdot( \pm r / \cdot)\end{array}$ & . & $\begin{array}{l}1 r / 19( \pm F / \Lambda) \\
1 \cdot / \cdot \wedge( \pm F / \Lambda) \\
1 \cdot / q \vee( \pm F / \vee) \\
11 / 9 r( \pm F / \Lambda) \\
9 / 9 F( \pm F / F)\end{array}$ & 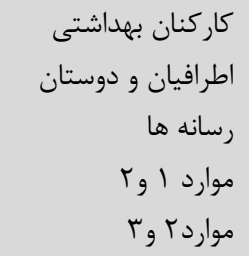 & منبع \\
\hline$\cdot 1 \cdot 1 \mathrm{~V}$ & 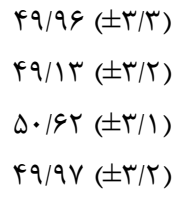 & r. & $\begin{array}{l}9 / 9 \Delta( \pm r / \cdot) \\
11 / 1 r( \pm / / V) \\
1 \cdot / 1 \wedge( \pm r / 1) \\
1 \cdot / \Delta \Delta( \pm I / V)\end{array}$ & $\cdot 190$. & $\begin{array}{l}11 / 11( \pm F / r) \\
11 / r \wedge( \pm F / \Lambda) \\
11 / \curlyvee \mid( \pm \Delta / 1) \\
11 / \wedge \&( \pm F / \vee)\end{array}$ & بيميمارى بيزيرى حاد بداد تب درن دار تب & علت مراجعه \\
\hline
\end{tabular}

جدول ب: تعيين آحاهى، نكرش و عملكرد مثبت نسبت به كنترل تب بر حسب متغيرهاى دموًرافيك كودى

\begin{tabular}{|c|c|c|c|c|c|c|c|}
\hline \multicolumn{2}{|c|}{ عملكرد } & \multicolumn{2}{|c|}{ ن نقرش } & \multicolumn{2}{|c|}{ آكاهى } & & \multirow[b]{2}{*}{ متغير ها } \\
\hline P-value & 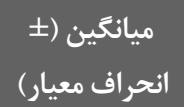 & P-value & 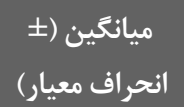 & P-value & 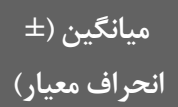 & & \\
\hline \multirow[t]{2}{*}{ •/ } & $\Delta \cdot / r \wedge( \pm r / r)$ & | I. & $1 \cdot / r \Delta( \pm r / 1)$ & \multirow{2}{*}{.1191} & II/A૬ $( \pm \Delta / 1)$ & يسر & \multirow{2}{*}{ جنس } \\
\hline & $\Delta \cdot( \pm r / l)$ & & $1 \cdot / r q( \pm 1 / \wedge)$ & & $\| / r r( \pm F / V)$ & دختر & \\
\hline \multirow[t]{2}{*}{$\cdot|| f \mid$} & $\Gamma \wedge / 1)( \pm r / r)$ & .1999 & $1 \cdot / \wedge 9( \pm r / 1)$ & \multirow{2}{*}{ - $/ Y Y q$} & $11 / \mathcal{F}( \pm F / V)$ & 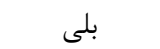 & \multirow{2}{*}{ علت } \\
\hline & $\Delta \cdot / r G( \pm r / V)$ & & $1 \cdot / r V( \pm r / \cdot)$ & & $\| / \& \mid( \pm F / \Lambda)$ & خير & \\
\hline \multirow[t]{2}{*}{$\cdot / \cdot V \cdot$} & $r q / V q( \pm r / q)$ & $\cdot / T \& D$ & $1 \cdot / \& V( \pm 1 / \Lambda)$ & \multirow{2}{*}{. /1MG } & $\| / \wedge \Delta( \pm \Delta / \mathscr{F})$ & بلى & \multirow{2}{*}{ به بسترى در كودى بيمارى منجر } \\
\hline & $\Delta \cdot / r \Delta( \pm r / 1)$ & & $1 \cdot / r \cdot( \pm r / \cdot)$ & & $11 / V \Delta( \pm F / V)$ & خير & \\
\hline \multirow[t]{2}{*}{$\cdot / r \Lambda$. } & $r q / q)( \pm r / F)$ & $\cdot 1119$ & $1 \cdot / 9 F( \pm T / T)$ & \multirow[b]{2}{*}{$\cdot 11 \cdot \Delta$} & $|r /| V( \pm \varepsilon / T)$ & بلى ل & \multirow{2}{*}{ ديخ بسترى خابقه بيمارى منجر فرزند } \\
\hline & $\Delta \cdot / r r( \pm r / r)$ & & $1 \cdot / r \cdot( \pm r / \cdot)$ & & $11 / \Delta \Lambda( \pm r / \Lambda)$ & خير & \\
\hline \multirow[t]{2}{*}{$\cdot / \Delta V Q$} & $\Delta \cdot / r V( \pm r / \cdot)$ & - MFE & $1 \cdot / \mu F( \pm 1 / 9)$ & \multirow{2}{*}{. /MFF } & $11 / V \Delta( \pm \mathbb{F} / \mathcal{F})$ & زايمان به موقع & \multirow{2}{*}{ وضعيت تولد } \\
\hline & F $/ \vee q( \pm r / r)$ & & $1 \cdot / 19( \pm r / 1)$ & & $1 \cdot / r G( \pm F / \Lambda)$ & نارس & \\
\hline
\end{tabular}




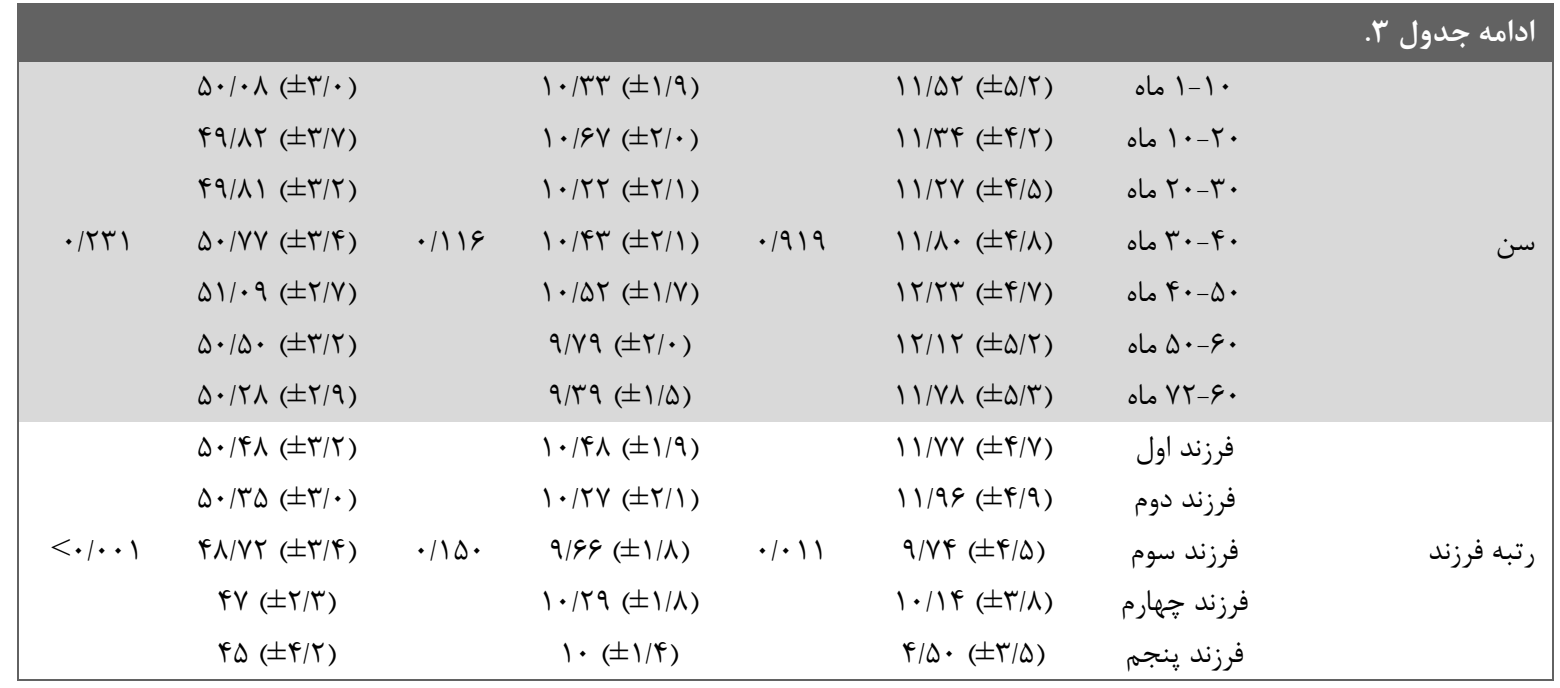

خصوص دماى طبيعى بدن و تعيين تب با دماسنج ضعيف

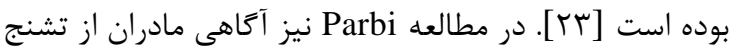

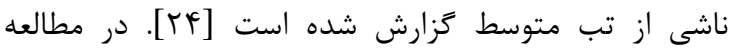

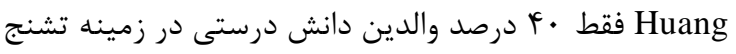

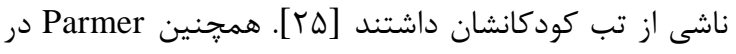

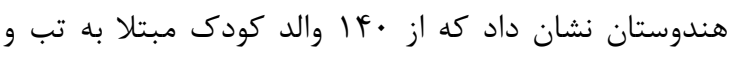

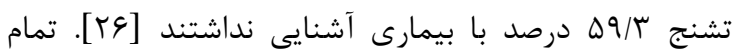

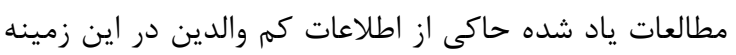

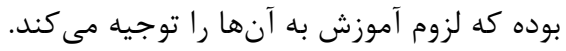

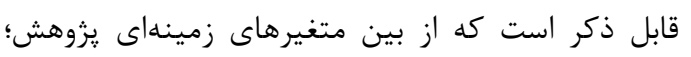

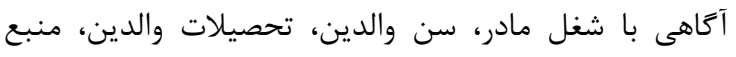

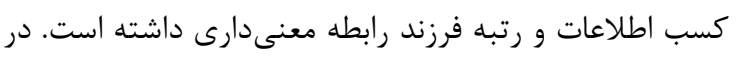

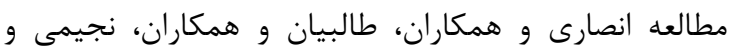

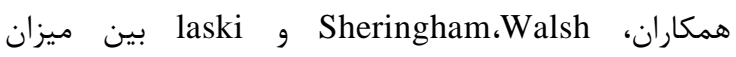
تحصيلات والدين و آحاهى والدين در مورد تب وتشنج رابطه

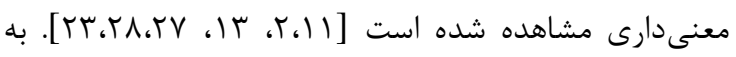

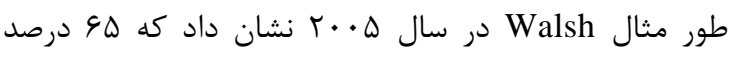

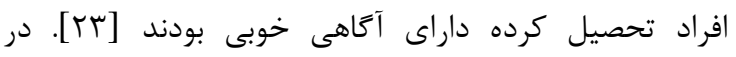

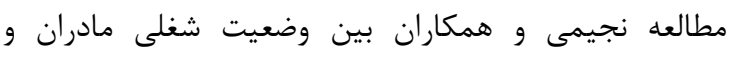

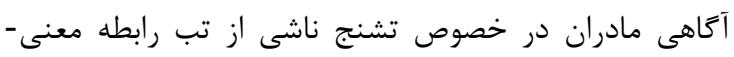

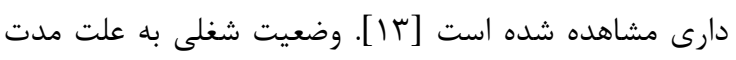

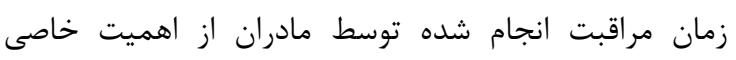

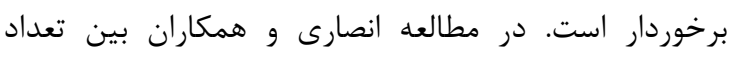

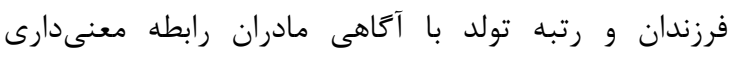

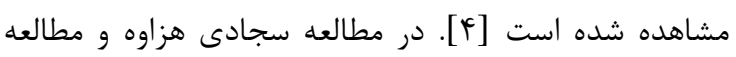

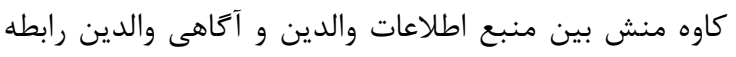

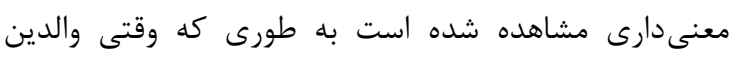

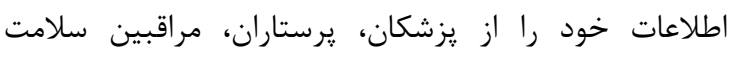

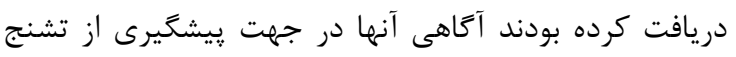

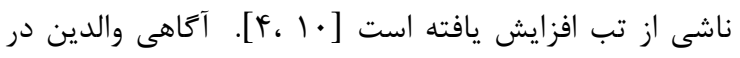

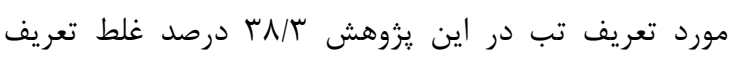

تب شامل پاشويه، كم كردن لباس كودى و خنك نحه داشتن

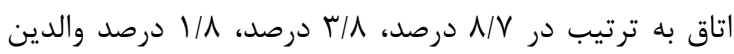

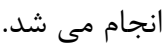

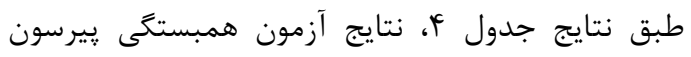

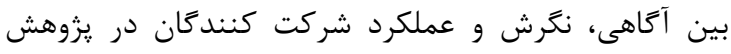
رابطه مثبت و معنى دارى مشاهده شد ( ( • P (P).

$$
\text { جدول f: ماتريس ضريب همبستخى پيرسون بين آكاهى، نكرش و }
$$

\begin{tabular}{|c|c|c|c|}
\hline عملكرد & ن نكرش & آكاهى & متغير هاى مطالعه \\
\hline & & 1 & آكاهى \\
\hline & 1 & $\cdot \pi \xi \cdot{ }^{* *}$ & نخرش \\
\hline 1 & $.1110^{*}$ & $\cdot \mid 4 \cdot 1^{* *}$ & عملكرد \\
\hline
\end{tabular}

بقث يافته هاى يزوهش حاضر حاصل نشان داد كه والدين

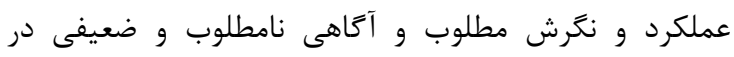

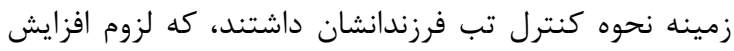
سطح آكاهى والدين از طرق مختلف مانند آموزش مستقيم و

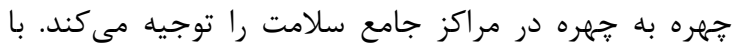

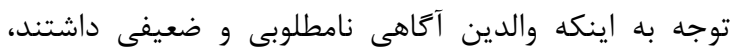
همسو با نتايج يزوهش حاضر، در مطالعه انصارى و همكاران

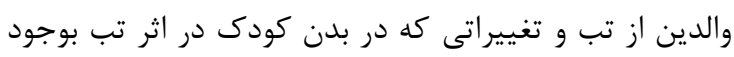

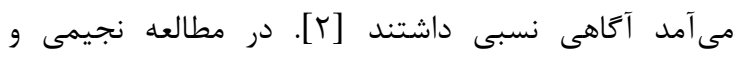

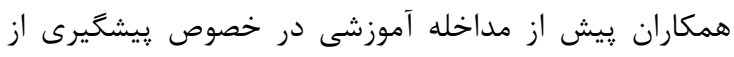

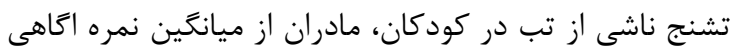

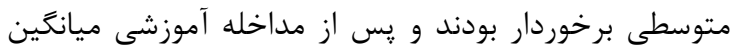

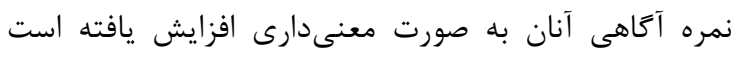

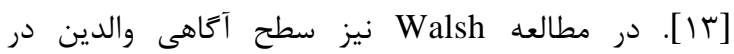


اداره تب كودكان در ممالك يِيشرفته نيز موجبات نكرانى

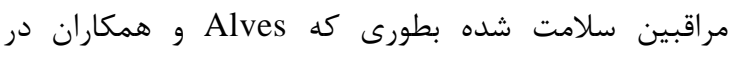

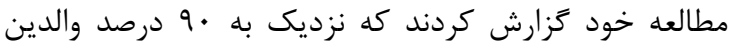

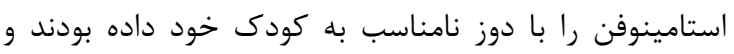

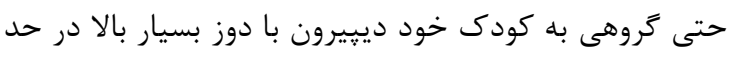

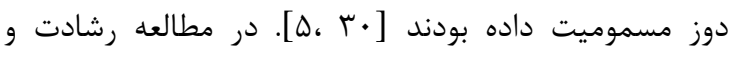

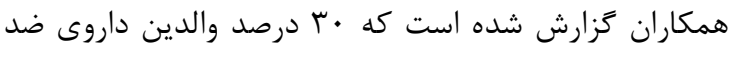

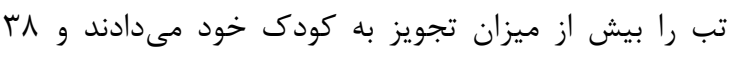

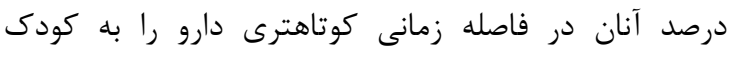
مى دادند در همين مطالعه تجويز استامينوفن به كودى دان به درانه

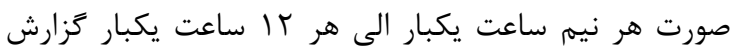

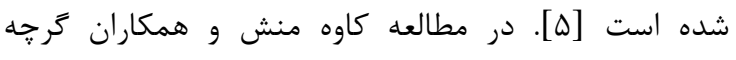
مادران داروهاى تب بر را مىشناختند ولى بسيارى از آنها.

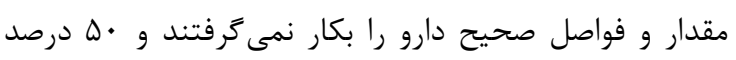
مادران مقدار دارو را بيشتر يا كمتر از مقدار لازم به كود دوكان

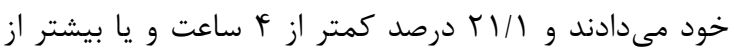

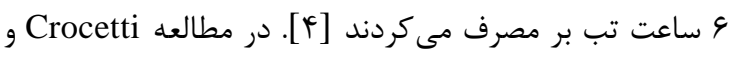

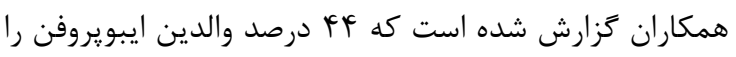

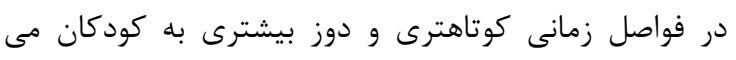

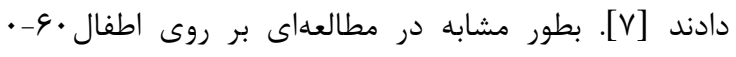

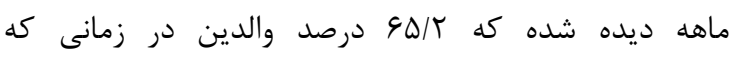

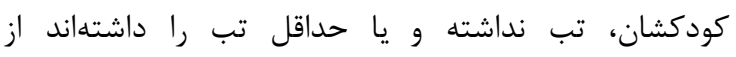

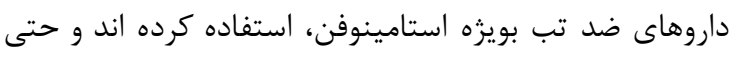

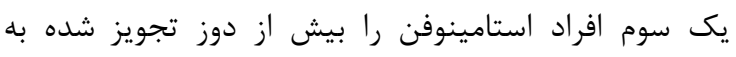

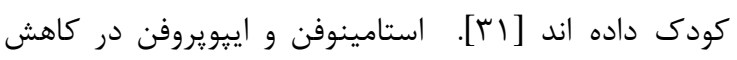
تب، ايمنى و توانايى مشابهى دارند و و ميزان صحيح

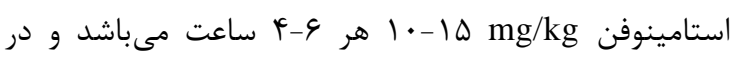

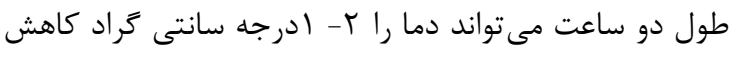

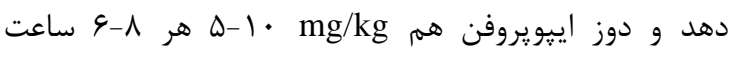

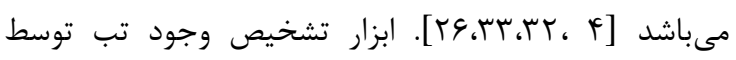

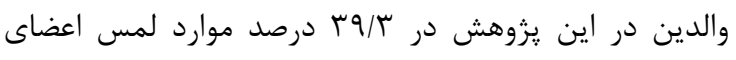

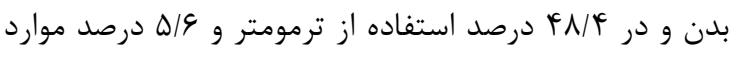

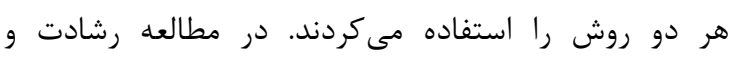

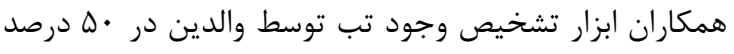

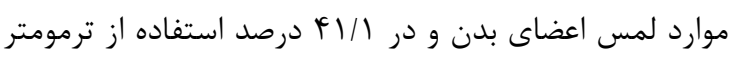

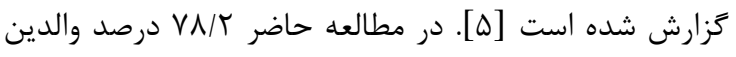

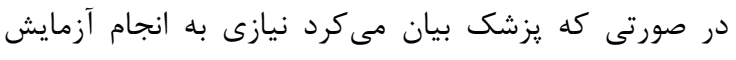

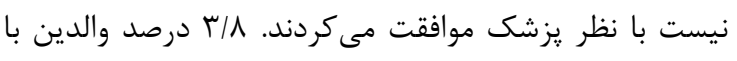

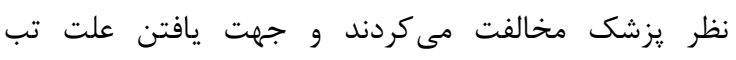

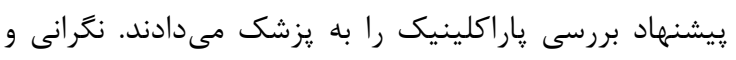

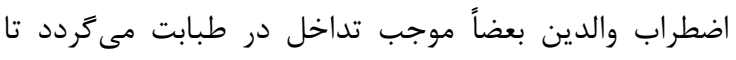

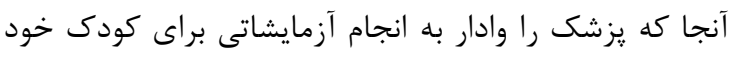

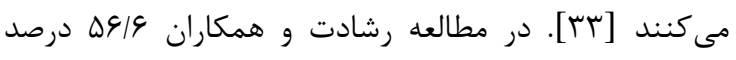

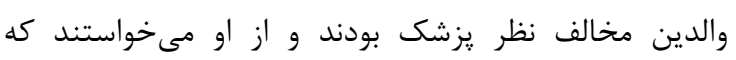

شده است. در مطالعه كاوه منش و همكاران MN/9 درصد هم

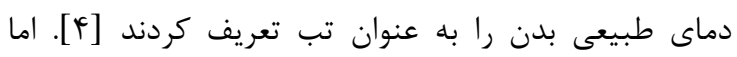

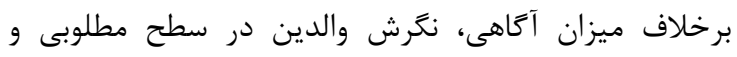

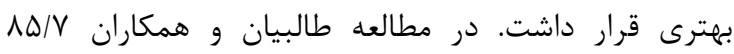

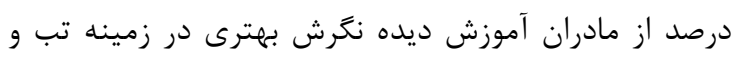

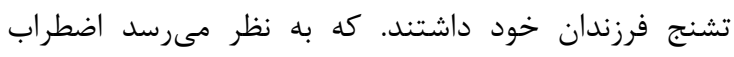
شديد مادران از تشنج ناشى از تب كه در بسيارى از مطالعات

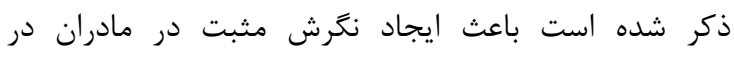
خصوص روشهاى كنترل تب و ييشخيرى از تشنج شده است

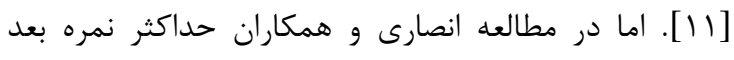

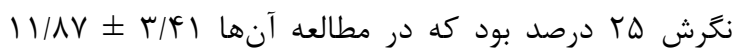
كزارش شده است و اين بدين معنى است كه نكخرش و ديد

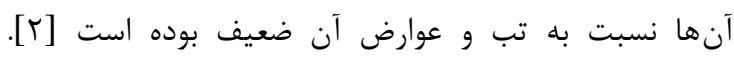

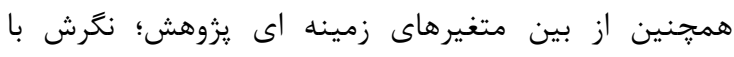

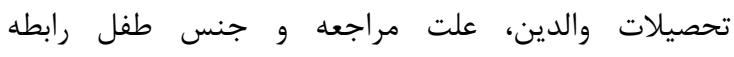

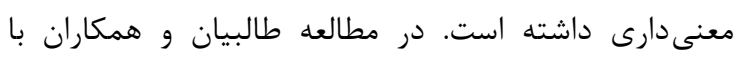

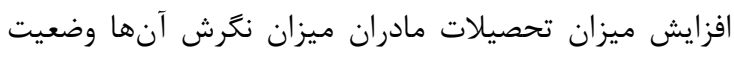
بهترى داشت [11].

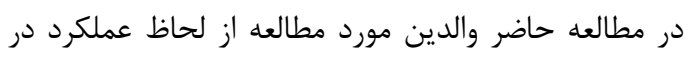

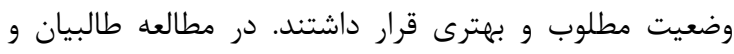

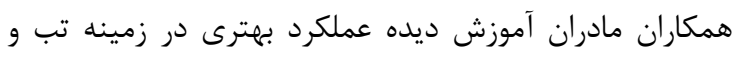
تشنج فرزندان خود داشتند [11]. در مطالعه نجيمى و و همكاران يس از مداخله آموزشى انجام شده با هدف كنترل تب مئن ميانكين

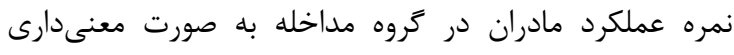

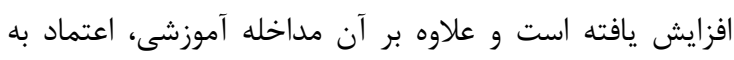
نفس و آرامش درونى ناشى از اقدام به موقع رافئ دا در مادران

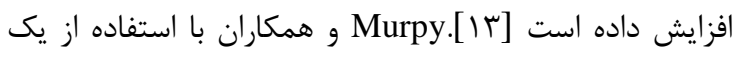

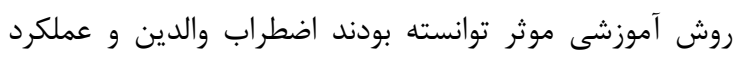

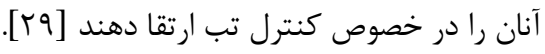

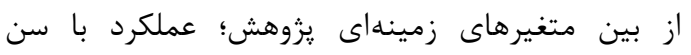

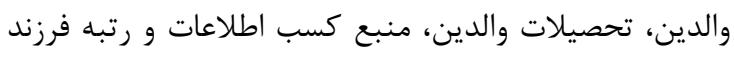

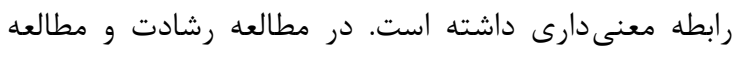
سجادى هزاوه بين عملكرد صحيح والدين و سطح تحصيلات

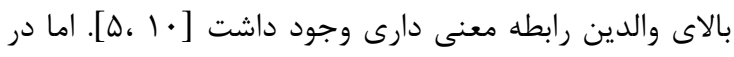

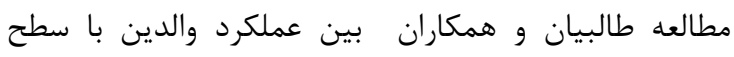

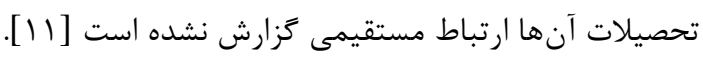

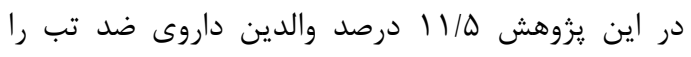

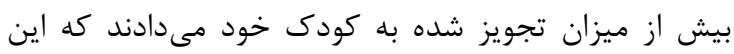

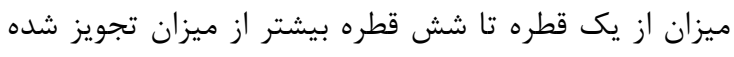

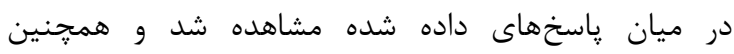

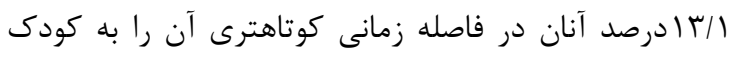

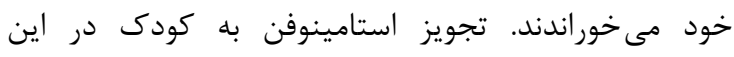

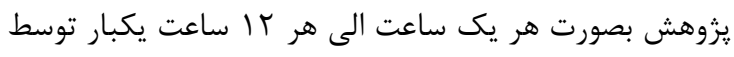

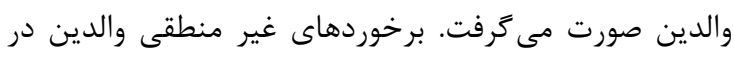


كه براى حل اين مشكل با صرف وقت بيشتر و توضيح و توجيه اهميت مطالعه سعى بر جلب نظر والدين واجد شرايط

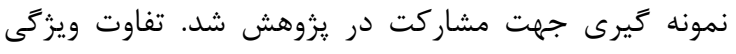

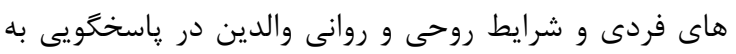

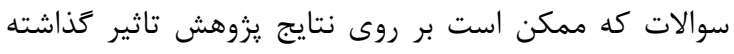

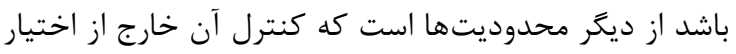
يزوهشخران بود.

\section{نتيجه تيرى}

با توجه به برآورد كلى يافته هاى مطالعه به نظر مىرسد

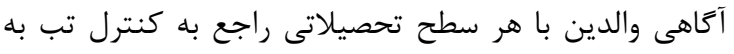

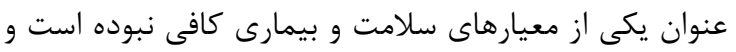

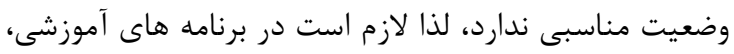

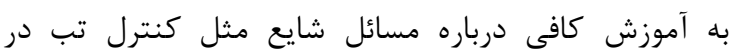

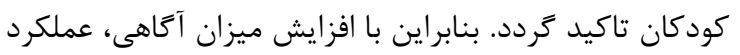

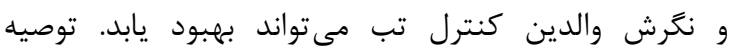

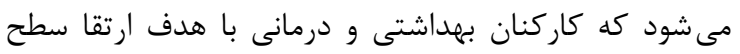

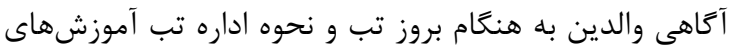

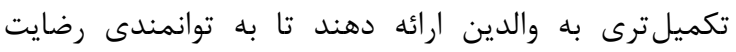
بخشترى جهت اداره تب فرزندانشان دست يابند. همجنين إندين

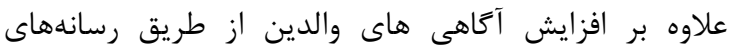

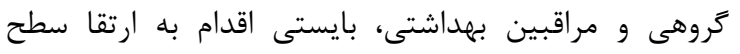
آكاهى مادران به طور اختصاصى كرد.

تشكر و قار فاذى

نويسندگان اين مقاله بر خود لازم مى دانداند، از ريشتيبانى

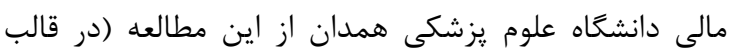

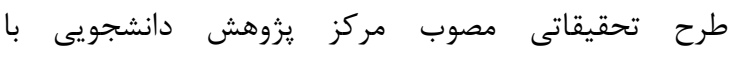

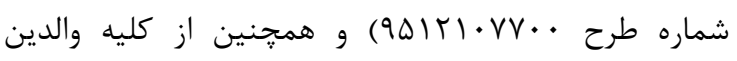
شركت كننده در مطالعه كه در كليه مراحل يزوهش محققين را يارى رساندند، تشكر و قدردانى بعمل آورند.

تضاد منافع اين مطالعه براى نويسنده هيج گونه تضاد منافعى نداشته

\section{REFERENCES}

1. Behrman, Kilegman, Jenson: Nelson textbook of pediatric 17th Ed. WB Saunders, Philadelphia, 2004; 839-849.

2. Ansari A, Ravanipour M, Jahanpour F, Hosseini S. The challenges of managing childhood fever by parents referred to health centers in Bushehr. Iran South Med J. 2015; 18(4):738-750. (Persian)

3. Grzadzinsk R, Lord C, Sanders J, Werling D, Vanessa H. Children with Autism Spectrum Disorder Who Improve with Fever:Insights from the Simons Simplex Collection. Autism Res2018; 11(1): 175-184.

4. Kavehmanesh Z, Amirsalari S, Khalili Matinzadeh Z,
آزمايشات ياراكلينيك را انجام دهد [ه].

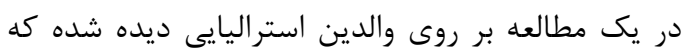

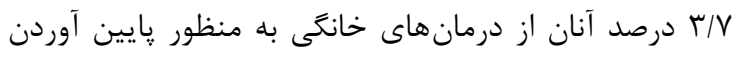

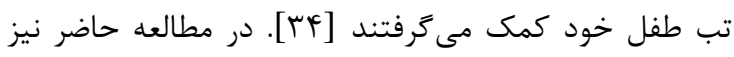

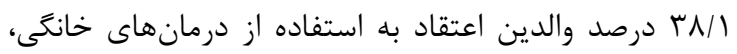
طب كياهى و سنتى داشتند كه در اين رابطه بيشترين كياه

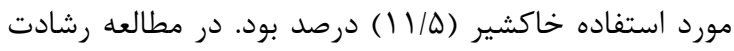

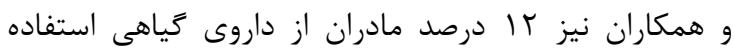
مى كردند كه 9/9 درصد آنها آنها از خاكشير استفاده مئ كردند

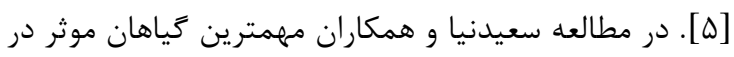

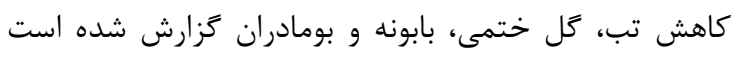

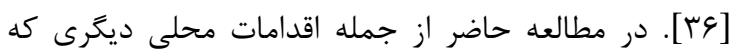
والدين براى كاهش تب انجام مى دادند ياشويه، كم كردن

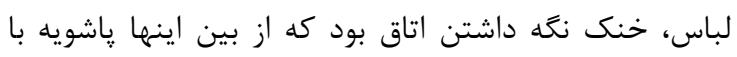

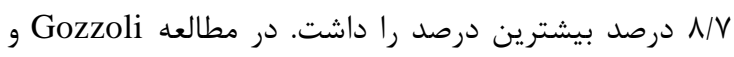

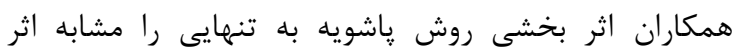

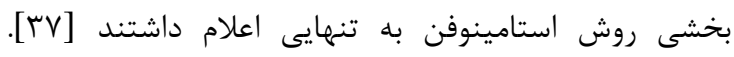

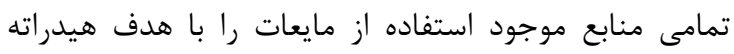

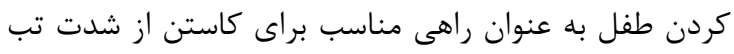

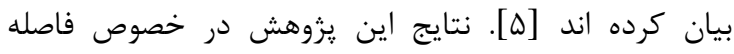

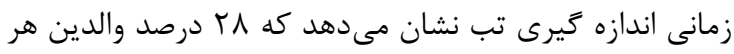

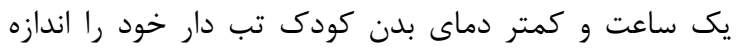

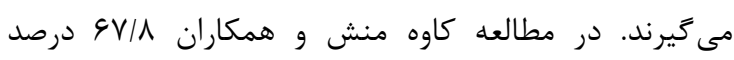

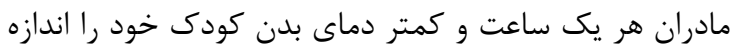

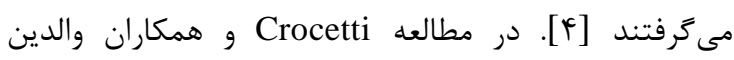
دماى بدن كودى تب دار را هر يكى ساعت ور و بيشتر اندازه

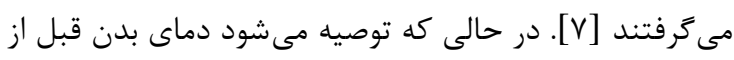

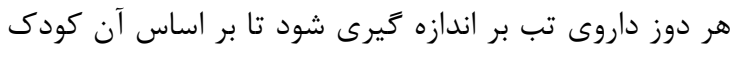

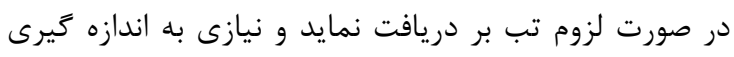

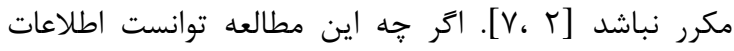

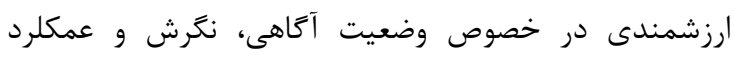
والدين در كنترل تب كودكان را بيان نمايد. وليكن از جمله

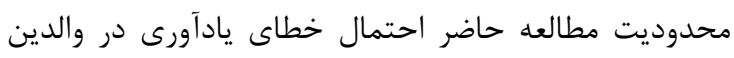

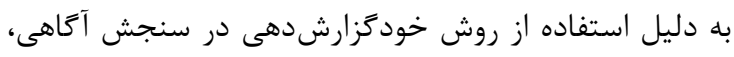

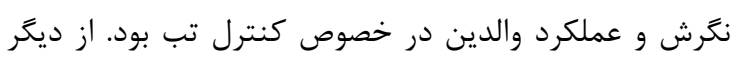

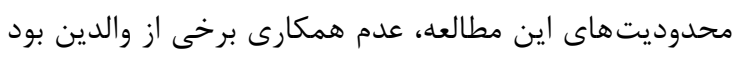

Baqheri K. Assessment of mothers' knowledge and attitudes of military families toward management of fever in their child. J Mil Med. 2008; 10(1):57-62. (Persian)

5. Reshadat S, SHakybaei D, Rezaei M, GHasemi R. Managing fever in parents of children under age 5 with fever. Sci J Hamadan Univ Med Sci. 2012; 19 (2): 28-33. (Persian)

6. Goldman RD, Scolnik D. Under dosing of acetaminophen by parents and emergency de-ferment utilization. J Pediatr Emerg Car. 2004; 20(2): 89-93.

7. Crocetti M, Moghbeli N, Serwint J. Fever phobia revisited; 
have parental misconceptions about fever changed in 20 years. Pediatrics. 2001; 107(6): 1241-6

8. Finkelstein JA, Christiansen CL, Platt R. Fever in pediatric primary care: occurrence, manage- ment, and outcomes. Pediatrics 2000; 105(1pt3): 260-266.

9. Karimi A, Armin SH, Fahmzade A. Febriel convulsion. Journal of Medical Council of Iran.2008; 26(2): 246-264. (Persian)

10. Sajadi Hazaveh M, Shamsi M. Assesment of mothers' behavior about prevention of febrile seizure in children in Arak city. Application of the Health Belief Model. J Jahrom Univ Med Sci. 2011; 9(2):34-40. (Persian)

11. Talebian A, Honarpisheh A, Barekatain B, Taghadosi M, Mousavi SGA. Evaluating of knowledge, attitude, practice and related factors in mothers of children with febrile convulsion at Kashan during 2006-2007. Feyz. 2009; 13(1):43-47. (Persian)

12. Nasehi MM, Moosazadeh M, Saket S, Bakhshandeh MK. Factor causes on the first febrile seizure in children: A systematic review. J Isfahan Med School. 2014; 32(289): 118. (Persian)

13. Najimi A, Dolatabadi N, Esmaeili AA, Sharifirad GH R. The effect of educational program on knowledge, attitude and practice of mothers regarding prevention of febrile seizure in children. Health sys Res. 2010; 6(4):744-751. (Persian)

14. Flury T, Aebi C, Donati F. Febrile seizures and parental anxiety: does information help? Swiss Med Wkly. 2001; 131(37-38): 556-60.

15. Tanja F, Christine A, Filippo D. Febrile seizures and parental anxiety. Does information help. Swiss Medd Wkly 2002;131(2):555-60.

16. Eissa YA, Zamil FA, Sanie AM, Salloum AA, Tuwaijri $\mathrm{HM}$, et al. Home management of fever in children; rational or ritual ? Int J Clin Pract. 2000; 54 (3) : 138- 42.

17. Al- Nouri L, Basheer K. Mother's perceptions of fever in children. J Trop Pediatr. 2005; 52: 113-6.

18. Aricav SG, Arica V, Onu H. Knowledge, attitude and response of mothers about fever in their children. Emerg Med J .2012; 29: e4

19. Krantz C. Childhood fevers: developing evidence based anticipatory guidance tool for parents. Pediatr Nurs2001; 27: 567-71.

20. Zeighami R, Haghi M, Bijani B, Alipour M, Kaboudi B, Haghi M. A comparison between cold water sponging and fanning in reducing fever in intensive care unit inpatients: a factorial design. Iran J Nurs Res. 2015; 10 (3):100-107. (Persian)

21. Hammond NE, Boyle M. Pharmacological versus nonpharmacological antipyretic treatments in febrile critically ill adult patients: a systematic review and meta-analysis. Australian Critical Care. 2011; 24(1):4-17
22. Gasemi F, Valizadeh F, Mohsenzadeh A. Educational n eeds of mothers of children with febrile convulsion, planetarium. J Khorramabad 2005; 1(1): 1-4. (Persian)

23. Walsh A, Edwards H. Management of childhood feverby parents: literaturereview. J Adv Nurs2006; 54: 217-27.

24. Parbi H, Neamatolahi A. Evaluation knowledge of parents of children with febrile convulsion, Medical University of khoramabad, shahid madani hospital. Iran Pediatric J. 2002; 26: 8-10. (Persian)

25. Huang MC, Liu CC, Huang CC. Effects of an educational program on parents with febrile convulsive children. Pediatr Ne ural 1998; 18(2): 150-5.

26. Parmar RC, Sahu DR, Bavdekar SB. Knowledge, attitude and practices of parents of children with febrile convulsion. Medneurology J 2001; 1(47): 19-23.

27. Sheringham A, Teodor M, Salci T. Febrile convulsions: development and validation of a questionnaire to measure parental knowledge, attitudes, concerns and practices. J Forms Med Assoc 2006;105(1):38-42.

28. Laski A, Chi YC, Thomas K, Huang MC, Liu CC, Huang CC. Parental concerns for the child with febrile convulsion: long-term effects of educational interventions. Acta Neurol Scand. 2001;103(5):288-93.

29. Murphy KA, Liebman M. Fever care: does nursing instruction make a difference? J Emerg Nurs. 1995; 21(5): 461-3.

30. Alves JG, Cardosoneto FJ, Alemedia CD, Almedia ND. Dipyrone and Acetaminophen: correct dosing by parents. Sao Paulo Med J 2007; 41-25(1):57-9.

31. Bilenko N, Tessler H, Okbe R, Press J, Goro discher R. Determinants of antipyrentic misuse in children up to 5 years of age: a cross- sectional study. Clin Thr 2006; 28(5): 783-93.

32. Behrman, Kilegman, Jenson: Nelson textbook of pediatric 17th Ed. WB Saunders, Philadelphia, 2004; 839-849.

33. Anthony J, Trevor Bertram G. Ktzung \& Trevores Pharmacology examination \& board review: $6^{\text {th }} \mathrm{ed}$. E Mc Growhill, Missour: 2002; 320-26.

34. Pursell E. Parental fever phobia and its evolu-tionary correlates. J Clin Nurs2009;18(2):210-18.

35. Walsh A, Edwards H, Fraser J. Over the counter medication use for child hood fever: a cross-sectional study of Australian parents. J Paediatr Child Health 2007; 43(19): 601-6.

36. Saeidnia S, Dasian Z, Hadjiakhoondi A. Herbal Medicines and Pediatric Diseases. JMP. 2010; 1 (33):16-25. (Persian)

37. Gozzoli V, Treggiari MM, Kleger GR, Roux-Lombard P, Fathi M, Pichard C, et al. Randomized trial of the effect of antipyresis by metamizol, propacetamol or external cooling on metabolism, hemodynamics and inflammatory response. Intensive Care Medicine. 2004;30(3):401-7. 